\title{
Reaching national consensus on the core clinical skill outcomes for family medicine postgraduate training programmes in South Africa
}

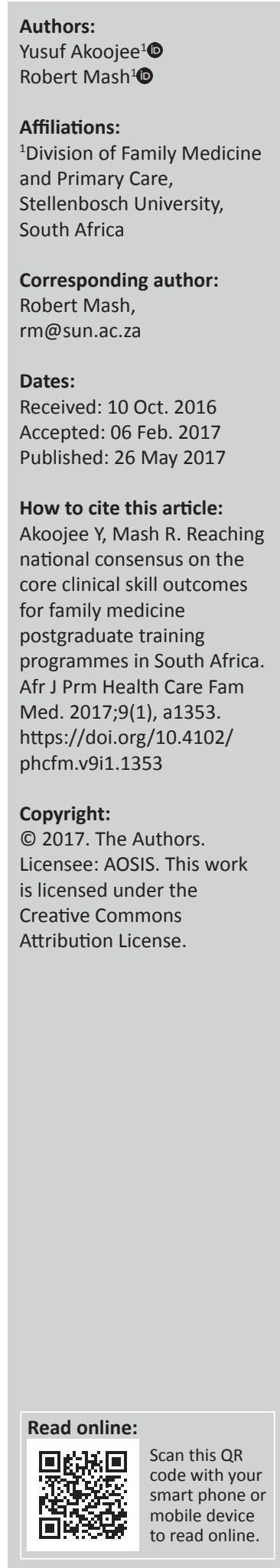

Background: Family physicians play a significant role in the district health system and need to be equipped with a broad range of clinical skills in order to meet the needs and expectations of the communities they serve. A previous study in 2007 reached national consensus on the clinical skills that should be taught in postgraduate family medicine training prior to the introduction of the new speciality. Since then, family physicians have been trained, employed and have gained experience of working in the district health services. The national Education and Training Committee of the South African Academy of Family Physicians, therefore, requested a review of the national consensus on clinical skills for family medicine training.

Methods: A Delphi technique was used to reach national consensus in a panel of 17 experts: family physicians responsible for training, experienced family physicians in practice and managers responsible for employing family physicians.

Results: Consensus was reached on 242 skills from which the panel decided on 211 core skills, 28 elective skills and 3 skills to be deleted from the previous list. The panel was unable to reach consensus on 11 skills.

Conclusion: The findings will guide training programmes on the skills to be addressed and ensure consistency across training programmes nationally. The consensus will also guide formative assessment as documented in the national portfolio of learning and summative assessment in the national exit examination. The consensus will be of interest to other countries in the region where training programmes in family medicine are developing.

\section{Introduction}

International policy guidelines stipulate that registrars in family medicine should be taught all the procedures within their scope of practice during training. The minimum requirement would be to cover all procedures typically performed by a substantial number of practising family physicians (FPs) in both ambulatory and inpatient settings. Ideally, these procedures should be taught by FPs and the list should be updated on a regular basis to include new or emerging procedures. ${ }^{1}$ Unfortunately, there is not always adequate coverage of all procedures or consistency between training programmes, even in the same country. An agreed national procedure list may help to guide training programmes. ${ }^{2}$

The training of family medicine registrars in clinical skills is a crucial element in the development of FPs for district health services in South Africa. ${ }^{3}$ FPs who are competent in a comprehensive range of clinical skills should be able to strengthen district health services and improve patient health outcomes. ${ }^{4}$ Competency in these clinical skills should ensure that patients are able to access care locally, thereby avoiding referral or further progression of their disease, when it may become more serious and costly to treat. ${ }^{5}$

FPs in South Africa serve a wide spectrum of patients. The clinical skills required by FPs are determined by the burden of disease, the settings where FPs work, the resource constraints of the health care system and the policy on the package of services expected. ${ }^{2}$ FPs should be familiar with the health needs in the communities they serve and should be equipped with and competent in performing the relevant clinical skills in order to manage patients comprehensively, thereby improving patient care and patient health outcomes. ${ }^{6}$

FPs work in a number of different care settings, such as the private or public health care sectors, rural or urban settings and community health centres or district hospitals. ${ }^{7}$ FPs who work in 
district hospitals require more procedural clinical skills compared to those who have chosen a career in primary care.

These diverse practice settings emphasise the significant role FPs play in the district health care system and the broad scope of practice required. In South Africa, FPs often work in remote or underserved communities where resources are scarce, emergency medical services limited and referral hospitals distant and overloaded, making it difficult to transfer patients. ${ }^{8}$

Patients that should be managed at a higher level are therefore often managed in the district health services, which puts further pressure on the clinical skills expected of FPs. Conversely, large urban district hospitals may also employ FPs and expect a range of skills more appropriate to regional or tertiary hospitals. Clinical skills training is therefore vital for family medicine registrars to prepare them for their involvement in inpatient district hospital and ambulatory primary health care. ${ }^{3}$

Since the official introduction of family medicine registrar training in South Africa, there have been two previous publications on the clinical skills required. The first study 'Building consensus on clinical procedural skills for South African family medicine training using the Delphi technique' proposed a set of essential clinical skills for the training of FPs, which served as a benchmark for South African family medicine training programmes. ${ }^{4}$

The second article 'Obtaining consensus on core clinical skills for training in family medicine' presented the final consensus of the College of Family Physicians and the Academy of Family Physicians on the required skills based on the prior research study. ${ }^{9}$ The final skills list produced represented the consensus of family medicine educators in South Africa and provided a basis for family medicine registrar training.

The departments of family medicine accepted that the agreed list was a dynamic one that may need to be updated to reflect changing circumstances and lessons learnt and proposed that the list be reviewed. ${ }^{9}$ This study, therefore, intends to revise and update the list of clinical skills, as it is now almost 10 years since the original work was done.

Refining the clinical skills required will help training programmes to revise their learning outcomes and to ensure consistency across training programmes nationally. The skills list also guides formative assessment and learning as documented in the national portfolio of learning as well as summative assessment in the national exit examination offered by the College of Family Physicians. The skills list also guides the type of rotations and clinical training required for each registrar in each specific training complex. The list can also guide quality management and assurance of the training programmes and supervisors.

The family medicine training programmes coordinate their activities with the help of the National Education and Training Committee of the South African Academy of Family
Physicians. This committee had specifically requested a review of the national consensus on clinical skills for family medicine training.

Postgraduate training in family medicine is also developing in many countries in sub-Saharan Africa, for example, Botswana, Zimbabwe, Kenya, Uganda, Nigeria and Ghana. ${ }^{10}$ This study will also be of interest to universities or colleges that are developing or revising curricula.

\section{Aim and objectives}

The aim was to reach a new national consensus on the clinical skill outcomes for family medicine postgraduate training programmes in South Africa. Objectives were as follows:

- to reach consensus on the clinical skills that should be retained from the current list

- to reach consensus on the clinical skills to be omitted from the current list

- to reach consensus on the clinical skills to be added to the list

- to reach consensus on the clinical skills that may be seen as optional or elective skills.

\section{Methods Study design}

The Delphi method was used to reach consensus on the clinical skills required amongst a group of experts from across the country. The key features of this design were anonymity of the panel members, iteration with controlled feedback from a series of questionnaires, quantitative analysis of the group's response and the use of explicitly defined expert opinion. ${ }^{11}$

\section{Study setting}

At the time of this study, there were eight postgraduate programmes in family medicine offered by the eight medical schools situated at the Universities of Cape Town, Stellenbosch, Free State, Witwatersrand, Pretoria, Limpopo, KwaZulu-Natal and Walter Sisulu. Training was organised in primary health care facilities and district and regional hospitals, with formal training posts and direct supervision by FPs or other specialists. Registrars rotated through the various facilities and clinical departments to attain the learning outcomes. The national portfolio of learning guided workplace-based training and assessment and included a logbook for assessment of competency in clinical skills. ${ }^{12}$ Registrars provided evidence in the portfolio of three years of full-time training in order to gain entrance to the national exit examination offered by the College of Family Physicians. The examination included assessment of clinical skills through written papers and an objective structured clinical examination and observation of consultation in three clinical cases.

Upon completion of training, FPs could apply for advertised FP posts in primary health care or district hospitals within the public sector or become general practitioners within the private sector. In the public sector, the role of the FP has been 
defined as a competent clinician able to work at the district hospital or in primary care, a consultant to the rest of the health care team, a capacity builder who strengthens the clinical skills of the whole team, a leader of clinical governance to improve the quality of care, a champion of communityorientated primary care and in some cases a supervisor or trainer of under- or postgraduate students. ${ }^{13}$

\section{Study population}

A panel of 36 experts was identified and invited to serve on the Delphi panel:

- heads of family medicine departments (eight people).

- postgraduate programme managers (eight people).

- experienced FPs in practice, four in primary care and four in district hospitals (eight people).

- managers in the Department of Health at national, provincial or district levels (eight people).

- specialists from other disciplines for specific high procedure areas - surgery, anaesthetics, obstetrics and orthopaedics - who are involved in training registrars in family medicine or district clinical specialist teams (four people).

\section{Data collection}

The Delphi technique uses an iterative strategy to gather information and arrive at consensus. The panel of experts were asked to respond to a series of questionnaires that were distributed to them electronically. It was anticipated by the research team that up to four rounds would be required to obtain consensus on all items.

The first questionnaire was based on the existing list of clinical skills, the current policy on the package of care required by district hospitals and primary care, as well as local research on skills required at district hospitals.

The participants were asked to select one of the following options for each clinical skill:

- retain skill - FPs must be competent to perform this skill

- delete skill - FPs do not need to perform this skill

- optional or elective skill - FPs may be required to perform this skill in certain limited settings such as rural or remote district hospitals

- space was provided for qualitative feedback on additional clinical skills that should be added or comments on the list of clinical skills.

The expert panel members were asked to respond to a series of three questionnaires, which were distributed to them electronically via email over a period of five months, from July to December 2015.

\section{Data analysis}

Demographic and profile data were collected on the panel members. Consensus was defined as $70 \%$ or more of the group agreeing on an option for that specific skill. The analysis involved descriptive statistics in terms of numbers and frequencies. Once consensus was reached, an item was removed from the questionnaire in the next round. Feedback was provided to the group on the responses of the panel in the previous round and the qualitative feedback was used to revise the questionnaire.

\section{Ethical consideration}

Ethical approval was obtained from the Stellenbosch Health Research Ethics Committee 1 via expedited review procedures with the protocol number (S14/07/157) on 15 October 2015.

\section{Results}

From the panel of 36 experts who were invited, 17 agreed (three heads of family medicine departments, three postgraduate programme managers, six experienced FPs; three managers from the Department of Health at national, provincial or district levels and two specialists from high specific procedure areas). Out of these 17 panel members, nine were located in the Western Cape, three in Eastern Cape, three in Gauteng, one in KwaZulu-Natal and one in the Free State. Six of the eight training programmes at the universities were represented (Walter Sisulu, Witwatersrand, KwaZuluNatal, Stellenbosch, Pretoria, Free State, but not Cape Town and Limpopo). Overall, 10 panel members were men and 14 respondents were aged between 45 and 64 years. Seventeen questionnaires were returned from each of the three rounds giving an overall response rate of $100 \%$ amongst those that consented.

\section{First questionnaire}

The first questionnaire contained a list of 238 clinical skills and consensus was reached on 193 of the skills in the first round where the panel decided that 187 skills should be retained and 6 skills should be made elective. The panel could not reach consensus on 45 skills from the first round.

\section{Second questionnaire}

All skills on which consensus had been reached in the first questionnaire (193 skills) were deleted from the second questionnaire. The results for the 45 skills on which there was no consensus from the first round were included in the second questionnaire and distributed to the panel members. In the second round, 17 skills were added from the qualitative feedback of the panel members in the first round. There were, therefore, a total of 62 skills in the second round. Consensus was reached on 42 clinical skills and the panel decided that 23 skills should be retained and 19 skills should be made elective. The panel could not reach consensus on 20 skills in the second round.

\section{Third questionnaire}

In the final round, the remaining 20 skills were again presented to the panel with the results obtained in the second round as feedback to the panel. Consensus was reached on 
nine clinical skills and the panel decided that six should be elective skills and three clinical skills should be deleted. The panel could not reach consensus on 11 skills in the last round.

\section{Final consensus}

The final consensus achieved for the clinical skills is presented in Tables 1-4.

\section{Discussion}

The skills list generated by this study represents a new national consensus on the clinical skill outcomes for postgraduate family medicine training programmes in South Africa. Consensus was reached on 242 core clinical skills, from which the panel decided that 211 should be retained, 3 should be deleted and 28 should be made elective. The panel could not reach consensus on 11 skills in the final questionnaire.

In a previous study, consensus was obtained on 168 core clinical skills that should be performed independently at the end of postgraduate training in South Africa. ${ }^{4}$ This study therefore reflects how family medicine training has expanded since the previous study was conducted in 2008 as an additional 43 skills were added to the new list. Many of the new skills are derived from additional roles that have been included in the list such as leadership of clinical governance, champion of community-orientated primary care and capacity building of the health care team through skills in teaching and learning. Previously, a more narrow definition of clinical skills was utilised, but in this study the panel felt these additional roles and their associated skills should be included.

While the 211 skills that were retained represent the core skills that every training programme should focus on, the list of elective skills is more open ended. The panel reached consensus on 28 skills that would typically be regarded as useful in some settings and would need to be mastered if the FP worked there. This list is however not exhaustive and other skills could be regarded as elective if the circumstances required them. Nevertheless, the 28 elective skills give some guidance to the training programmes on additional skills that may be needed.

The underlying assumption in the training programmes is that FPs should be prepared to work across the district hospital-primary care dyad. Often, the FP moves between both these settings and, for example, may be on call in the district hospital and providing outreach and support to primary care. In some settings, particularly metropolitan areas, the FP may only work in primary care and the list of required skills will be reduced. Nevertheless, every FP on qualifying should be competent to work across the whole district health system.

One way in which training programmes might decide on operationalising the elective list is by individualising each
TABLE 1: Core clinical skills for the training of family physicians $(N=17)$

\begin{tabular}{|c|c|}
\hline Consensus score $(\%)$ & Clinical skill \\
\hline \multicolumn{2}{|c|}{ Perform common side-room tests } \\
\hline 88 & Use a glucometer \\
\hline 88 & Use a haemoglobinometer \\
\hline 88 & Perform a pregnancy test \\
\hline 94 & Perform urinalysis \\
\hline 94 & Venepuncture \\
\hline \multicolumn{2}{|l|}{ Adult health - general } \\
\hline 94 & Femoral vein puncture \\
\hline 100 & Lumbar puncture \\
\hline 88 & Routine intravenous access in adults \\
\hline 88 & Lymph node excision biopsy \\
\hline 77 & Perform point-of-care testing for HIV \\
\hline \multicolumn{2}{|c|}{ Adults - musculoskeletal } \\
\hline 82 & Measure shortening of the legs \\
\hline 94 & Aspirate and inject the knee joint \\
\hline 94 & Inject tennis elbow or golfer's elbow \\
\hline 100 & Interpret radiographs of joints \\
\hline 82 & Inject carpal tunnel syndrome \\
\hline 76 & Inject De Quervain's tenosynovitis \\
\hline 82 & Inject the shoulder and subacromial bursa \\
\hline 77 & Inject trochanteric bursitis \\
\hline \multicolumn{2}{|l|}{ Adults - abdomen } \\
\hline 94 & Test stool for occult blood \\
\hline 100 & Incision and drainage of perianal haematoma \\
\hline 100 & Interpret the abdominal radiograph in an adult \\
\hline 94 & Proctoscopy \\
\hline 76 & Interpret barium swallows \\
\hline \multicolumn{2}{|l|}{ Adults - chest } \\
\hline 100 & Electrocardiogram set up, record and interpret \\
\hline 100 & Interpret chest radiograph \\
\hline 100 & Measure peak expiratory flow \\
\hline 94 & Nebulise a patient \\
\hline 100 & Pleural tap \\
\hline 100 & Use inhalers and spacers \\
\hline 88 & Exercise stress test \\
\hline 70 & Perform and interpret office spirometry \\
\hline \multicolumn{2}{|l|}{ Adults - urology } \\
\hline 100 & Penile block \\
\hline 100 & Reduce a paraphimosis \\
\hline 100 & Circumcision \\
\hline 100 & Drain hydrocele \\
\hline 94 & Insert a urinary catheter \\
\hline 94 & Insert a suprapubic catheter \\
\hline 82 & Interpret intravenous pyelogram \\
\hline 76 & Vasectomy \\
\hline \multicolumn{2}{|l|}{ Eyes } \\
\hline 70 & Subconjunctival injections \\
\hline 70 & Use a Schiotz tonometer \\
\hline 100 & Fundoscopy (diabetes, hypertension) \\
\hline 88 & Instil drops or apply ointment \\
\hline 100 & Remove foreign body from the eye \\
\hline 100 & Test for squint \\
\hline 100 & Washout of eyes (chemical burns) \\
\hline \multicolumn{2}{|l|}{ Ear, nose and throat } \\
\hline 82 & Assess hearing loss \\
\hline 82 & Reduce a fractured nose \\
\hline 100 & Remove a foreign body from ear and nose \\
\hline 100 & Syringe, dry swab an ear \\
\hline 94 & Take a throat swab \\
\hline 100 & Manage epistaxis (cautery, packing) \\
\hline 82 & Perform Rinne and Weber tests \\
\hline
\end{tabular}

Table 1 continues on the next page - 
TABLE 1 (Continues...): Core clinical skills for the training of family physicians $(N=17)$.

\begin{tabular}{ll}
\hline Consensus score $(\%)$ & Clinical skill \\
\hline 100 & Suture a pinna lobe
\end{tabular}

$82 \quad$ Drain a peritonsillar abscess

Skin

82

82

100

100

100

100

100

\section{Pregnancy}

94

100

94

100

94

94

94

100

100

94

100

94

100

100

94

82

Woman's health

88

100

82

70

100

100

88

88

76

94

88

71

\section{Newborn}

100

100

100

100

94

Consultation

100

100

100

100

100

100

100

100

94

100

94

100

100

100
Phenol ablation of ingrown toenail

Excise sebaceous cyst (other lumps, bumps)

Apply a compression dressing to venous leg ulcer

Cryotherapy or cauterisation

Skin biopsy (punch and shave) or skin scrapes

Wide-needle aspiration biopsy lymph node

Obstetric ultrasound

Interpret antenatal growth chart

Assess foetal well-being during labour

Episiotomy and suturing

Examine a pregnant woman

Examine progress during labour and use partogram

Normal vaginal delivery

Speculum examination

Apply and interpret the cardiotocograph

Assess foetal movement

Assisted vaginal delivery or vacuum extraction or forceps

Caesarean section

Manual removal of placent

Repair of third-degree tear

Pelvic ultrasound (transvaginal)

Culdocentesis

Hormone implants

Laparotomy for ectopic pregnancy

Termination of pregnancy

Insertion of intrauterine contraceptive device

Papanicolaou smears

Dilatation and curettage

Drainage of Bartholin's abscess or cyst

Endometrial biopsy or sampling

Fine-needle aspiration biopsy of breast lump

Tubal ligation

Cervical polyp removal

Well newborn check

Assess gestational age at birth

Kangaroo mother care

Resuscitate a newborn

Umbilical vein catheterisation

Patient-centred consultation

Use genogram and eco-map

Develop and use flowcharts for chronic care

Motivate behaviour change

Assess and consult families, couples

Shared consultation to capacitate nurse practitioner

Counselling skills for HIV, termination of pregnancy, sexual assault

Break bad news

Mini-Mental State Examination

Use problem-orientated medical record

Conduct a family conference

Cope with language barriers

Holistic assessment and management

Sexual history and counselling
Inject keloids

Evacuation of uterus

TABLE 1 (Continues...): Core clinical skills for the training of family physicians $(N=17)$.

\begin{tabular}{ll}
\hline Consensus score (\%) & Clinical skill \\
\hline Emergency & \\
100 & Calculate \% burn \\
100 & Manage choking \\
94 & Give oxygen \\
100 & Immobilise spine \\
100 & Intubate and manage airway \\
94 & Measure the Glasgow Coma Scale \\
94 & Administer rabies prophylaxis \\
100 & Advanced cardiopulmonary resuscitation - Adult \\
94 & Advanced cardiopulmonary resuscitation - Child \\
100 & Debride wounds or burns \\
100 & Gastric lavage \\
100 & Give a blood transfusion \\
100 & Incision and drainage of abscesses \\
100 & Insert chest drain \\
100 & Insert nasogastric tube \\
100 & Interpret radiographs in trauma \\
88 & Intravenous cut down \\
94 & Manage snake bite \\
100 & Primary survey \\
100 & Relieve tension pneumothorax \\
100 & Remove a splinter fish hook \\
100 & Secondary survey \\
88 & Selecting emergency equipment for doctors' bag or \\
94 & emergency tray \\
82 & Suture lacerations \\
76 & Transport critically ill \\
\hline 70 & Insert central line \\
\hline 9 &
\end{tabular}

Orthopaedics

94

94

100

88

94

82

94

100

82

88

76

76

76

\section{Anaesthetics}

94

100

94

88

94

82

82

82

94

82

88

82

88

94
Apply finger and hand splints

Apply casts to upper and lower limb

Closed reductions for hand, forearm, tibia, fibula

Set up traction skeletal and skin

Reduce elbow dislocation

Reduce hip dislocation

Reduce radial head dislocation

Reduce shoulder dislocation

Excise ganglion

Amputations - fingers

Apply club foot cast

Debridement of open fractures

Fasciotomy

Injections - intra-dermal, subcutaneous, intramuscular, deep intramuscular, sub-conjunctival

Ring block

Administer oxygen

Check Boyle's machine

Control airways with mask

General anaesthetic

Inhalation induction

Intravenous induction

Intubate and ventilate patient

Ketamine anaesthesia

Monitor patient during anaesthetic

Recover patient - recovery room

Reverse muscle relaxation (mixed drugs)

Set airflow - Magill Circle, T-piece

Spinal anaesthetic 
TABLE 1 (Continues...): Core clinical skills for the training of family physicians $(N=17)$.

\begin{tabular}{ll}
\hline Consensus score (\%) & Clinical skill \\
\hline 70 & Sterilise equipment \\
94 & Ventilate patient mask and hand \\
76 & Biers block \\
82 & Brachial block
\end{tabular}

\section{Child health}

\section{Clinical administration}

100

100

100

100

100

76

Forensic

100

100

100

100

\section{Palliative care}

100

70

76

Clinical governance

100

100

100

100

100

100

76

94

\section{Community-orientated primary care}

94

100

100

Teaching and training

100

100

100

100

100
Assess growth and classify malnutrition

Capillary blood sampling - finger and hee

Chest radiograph in child

Developmental assessment

How to do and interpret Tine and Mantoux tests

Intraosseous line

Intravenous access in a child

Lumbar puncture in a child

Manage problems using the integrated management of childhood

Suprapubic bladder puncture

Venepuncture - upper limb and external jugular vein

Manage neonatal jaundice with phototherapy

Complete sick certificates

Complete death certificates

Certify patient under Mental Health Care Act

Making appropriate referrals and letters

Managing a clinic for chronic care, for example, HIV and

Perform work assessment and complete disability gran forms

Assess, manage and document drunken driving Assess, manage and document interpersonal violence Assess, manage and document sexual assault Complete J-88 form following assault

Counselling of a dying patient

Hypodermoclysis (subcutaneous infusion)

Set up a syringe driver

Able to contribute to the development or revision of guidelines

Able to facilitate the implementation of clinical guidelines within the subdistrict

Able to improve quality of care by facilitating quality improvement cycles (including the audit of clinical care as one step in the cycle)

Able to improve cost-effectiveness through reflection on routinely collected data, particularly rational prescribing and use of investigations

Build capability and quality care through teaching, training and mentoring

Able to critically appraise new evidence

Able to appraise the competence of new clinicians and set appropriate levels of independence versus support

Able to evaluate the quality of care in relation to the relevant clinically orientated national core standards

Able to do a home visit

Able to make a community diagnosis, and interpret and prioritise health indicators

Able to promote health in communities

Able to plan and implement a teaching or continuing professional development activity

Able to use a portfolio of learning

Able to mentor a colleague

Able to facilitate small group learning

Able to prepare and give a presentation
TABLE 2: Skills not needed in the training of family physicians $(N=17)$.

\begin{tabular}{ll}
\hline Consensus score (\%) & Clinical skills \\
\hline Adults - abdomen & Anal dilatation \\
76 & \\
Adults - urology & El-Ghorab shunt for priapism \\
88 & $\begin{array}{l}\text { Subjective refraction and dispense 'stock' } \\
\text { Eyes }\end{array} 82$ \\
\hline
\end{tabular}

TABLE 3: Optional or elective skills that are required in certain limited settings such as rural or remote district hospitals.

\begin{tabular}{|c|c|}
\hline Consensus score $(\%)$ & Clinical skills \\
\hline \multicolumn{2}{|c|}{ Perform common side-room tests } \\
\hline 76 & $\begin{array}{l}\text { Microscopy of vaginal discharge (wet mount, } \\
\text { potassium hydroxide) }\end{array}$ \\
\hline \multicolumn{2}{|l|}{ Adult health - general } \\
\hline 76 & Bone marrow puncture technique and smear \\
\hline 76 & Microscopy of cerebrospinal fluid \\
\hline 94 & Thin and thick smears for malaria \\
\hline \multicolumn{2}{|l|}{ Adults - abdomen } \\
\hline 76 & Abdominal ultrasound \\
\hline 70 & Anal sphincterotomy \\
\hline 88 & Gastroscopy \\
\hline 76 & Helicobacter pylori testing \\
\hline 76 & Peritoneal dialysis \\
\hline 88 & Repair a hernia \\
\hline 88 & Sigmoidoscopy \\
\hline 76 & Liver biopsy \\
\hline \multicolumn{2}{|l|}{ Adults - chest } \\
\hline 76 & Echocardiogram \\
\hline \multicolumn{2}{|l|}{ Adults - urology } \\
\hline 76 & Hydrocoelectomy \\
\hline 82 & Bilateral capsular orchidectomy \\
\hline 76 & Cystoscopy \\
\hline 76 & Prostate biopsy \\
\hline \multicolumn{2}{|l|}{ Eyes } \\
\hline 82 & Slit-lamp examination \\
\hline \multicolumn{2}{|l|}{ Ear, nose and throat } \\
\hline 82 & Indirect laryngoscopy \\
\hline \multicolumn{2}{|l|}{ Woman's health } \\
\hline 76 & Cone biopsy of cervix \\
\hline 71 & Colposcopy \\
\hline 76 & Hysterectomy \\
\hline 76 & $\begin{array}{l}\text { Large loop excision of the transformation zone } \\
\text { for cervix }\end{array}$ \\
\hline \multicolumn{2}{|l|}{ Orthopaedics } \\
\hline 70 & Open reductions - pins and screws \\
\hline \multicolumn{2}{|l|}{ Child health } \\
\hline 71 & Extradural tap \\
\hline \multicolumn{2}{|l|}{ Dental } \\
\hline 76 & Dental extraction \\
\hline 70 & Wiring of teeth for mandibular fracture \\
\hline \multicolumn{2}{|l|}{ Forensic } \\
\hline 82 & Medico legal post-mortem \\
\hline
\end{tabular}

registrar's future practice intent. For example, those intending to work in remote rural areas may require additional skills. Provinces may also have specific expectations of the skill set required of FPs.

In countries such as Canada and Australia, family medicine residency programmes offer a one- to two-year advanced procedural training course upon completion of family 
TABLE 4: Skills for which no consensus could be reached.

\begin{tabular}{|c|c|c|c|}
\hline Clinical skills & Retain (\%) & Delete $(\%)$ & Elective (\%) \\
\hline \multicolumn{4}{|l|}{ Perform common side-room tests } \\
\hline Microscopy of urine & 47 & & 53 \\
\hline \multicolumn{4}{|l|}{ Adult health - general } \\
\hline $\begin{array}{l}\text { Doppler ultrasound - For } \\
\text { peripheral vascular disease }\end{array}$ & 30 & 6 & 64 \\
\hline \multicolumn{4}{|l|}{ Adults - abdomen } \\
\hline Appendicectomy & 53 & 6 & 41 \\
\hline Injection of haemorrhoids & 41 & & 59 \\
\hline Rubber-banding of haemorrhoids & 35 & 6 & 59 \\
\hline \multicolumn{4}{|l|}{ Adults - chest } \\
\hline Pleural biopsy & 65 & & 35 \\
\hline \multicolumn{4}{|l|}{ Ear, nose and throat } \\
\hline Tonsillectomy or adenoidectomy & 41 & 12 & 47 \\
\hline \multicolumn{4}{|l|}{ Skin } \\
\hline Skin patch testing & 24 & 12 & 64 \\
\hline \multicolumn{4}{|l|}{ Pregnancy } \\
\hline Clinical pelvimetry & 47 & 35 & 18 \\
\hline Amniocentesis & 18 & 24 & 58 \\
\hline \multicolumn{4}{|l|}{ Anaesthetics } \\
\hline Epidural & 53 & 6 & 41 \\
\hline
\end{tabular}

medicine training. ${ }^{14,15}$ In Australia, training for ambulatory general practice and for rural medicine are separated, whereas in South Africa these two have been combined into one training programme. In South Africa and India, the need for FPs to have an extended range of skills in anaesthesia, obstetrics and surgery is clear. This may create a tension between training FPs to offer these more procedural skills, for example at the district hospital, where such skills are often missing, versus training them to be primarily part of the primary care team, as in Brazil or China. ${ }^{16}$

A similar study conducted in Canada only identified 65 core clinical skills and 15 enhanced skills and emphasised that physicians who worked in more rural areas were more likely to perform more of the core clinical skills as opposed to their counterparts in urban settings. ${ }^{14}$ A more recent study in Australia produced a list of 112 procedural skills that should be taught in general practice vocational training. ${ }^{15}$ No comparable lists were found for clinical skill outcomes or procedural skills for family medicine residencies in China, India, Brazil or other African countries.

In South Africa, there is still ambivalence amongst policymakers about the role of the FP, and we hope that experience with current FPs and the national position paper as well as ongoing research will help to establish consensus on the contribution of the FP and the need for a trained expert generalist as part of the system. ${ }^{13}$

\section{Limitations}

Only 17 of the 36 invited panel members agreed to participate in the study; therefore, this study was more limited in its representation of experts than intended. There were no representatives from the Universities of Cape Town and Limpopo and none from the provinces of North West, Northern Cape, Limpopo and Mpumalanga. However, the health needs of the provinces that were included are likely to be similar to those omitted and included both urban and rural populations. The two training programmes were also unlikely to have widely differing views to their colleagues. Overall, there was a balance of different categories of experts although fewer than intended in each category. No specialists in surgery and orthopaedics were included.

\section{Recommendations}

The findings of this study will be considered by the National Education and Training Committee of the South African Academy of FPs in order to approve changes to the national learning outcomes and to decide how to handle the skills on which no consensus could be reached. Out of the 11 skills on which no consensus was reached, the panel agreed (> 70\%) that 10 of them should not be deleted and therefore they should be considered for inclusion as at least elective skills. The panel had no consensus on retaining clinical pelvimetry as a skill, and it may be necessary to review the evidence in order to make a decision. It is important that the consensus of the panel be consistent with the latest evidence on the effectiveness of clinical skills, particularly when no consensus was reached. The recommendations of the Academy will also be presented to the College of Family Physicians to ensure that the national examination takes the new consensus into account.

Training programmes should then ensure that all registrars have the opportunity to become competent in these skills and that their learning is adequately recorded in the portfolio of learning, which will also need to be adapted. Clinical trainers must also be able to create a conducive learning environment within which they can observe clinical skills and give skilful feedback. The Academy is pioneering a short course for the training of clinical trainers and a process of quality assurance to raise the standard of clinical training across all programmes.

Policymakers and managers who are responsible for the district health services as well as health care providers and funders in the private sector should take cognisance of the clinical skills set defined in this study for the training of FPs. This may help them in understanding the roles and competencies of the FP and their contribution within the health care system.

\section{Conclusion}

This study defined a new set of clinical skills for the training of FPs in South Africa which consists of 211 core skills and 28 elective skills. Consensus could not be reached on 11 other clinical skills. The professional bodies for the discipline of family medicine must revise the national learning outcomes and national examination and training programmes to be aligned with this new consensus on the required clinical skills.

\section{Acknowledgements}

The authors are grateful to all the panel members who participated in the Delphi process. 


\section{Competing interests}

The authors declare that they have no financial or personal relationships that may have inappropriately influenced them in writing this article.

\section{Authors' contributions}

Y.A. performed the research study for his MMed degree under the supervision of R.M. Both Y.A. and R.M. approved the final article for publication.

\section{References}

1. American Academy of Family Physicians. Procedural skills, scope of training in family medicine residencies [homepage on the Internet]. [cited 2017 Feb 5] Available from: http://www.aafp.org/about/policies/all/procedural-skills-scope. html

2. Tenore JL, Sharp LK, Lipsky MS. A national survey of procedural skill requirements in family practice residency programs. Fam Med. 2001;33(1):28-38.

3. De Villiers MR, De Villiers PJ. The knowledge and skills gap of medical practitioners delivering district hospital services in the Western Cape, South Africa. S Afr Fam Pract. 2006;48(2):16-16c. https://doi.org/10.1080/20786204.2006.10873333

4. Mash B, Couper I, Hugo J. Building consensus on clinical procedural skills for South African family medicine training using the Delphi Technique. S Afr Fam Pract. 2006;48(10):14-14e. https://doi.org/10.1080/20786204.2006.10873475

5. Swanepoel M, Mash B, Naledi T. Assessment of the impact of family physicians in the district health system of the Western Cape, South Africa. Afr J Prim Health Care Fam Med. 2014;6(1):1-8. https://doi.org/10.4102/phcfm.v6i1.695
6. Starfield B, Shi L, Macinko J. Contribution of primary care to health systems and health. Milbank Q. 2005;83(3):457-502. https://doi.org/10.1111/j.14680009.2005.00409.x

7. Mash R, Reid S. Statement of consensus on family medicine in Africa. Afr J Prm Health Care Fam Med. 2010;2(1):Art. \#151, 1-4. https://doi.org/10.4102/ phcfm.v2i1.151

8. Hill P. Procedural skills in rural practice - A practice profile. S Afr Fam Pract. 1995;16(10):674-676.

9. Mash B, Couper I. Obtaining consensus on core clinical skills for training in family medicine. S Afr Fam Pract. 2008;50(6):69-73. https://doi.org/10.1080/2078620 4.2008.10873796

10. Mash RJ, De Villiers MR, Moodley K, Nachega JB. Guiding the development of family medicine training in Africa through collaboration with the medical education partnership initiative. Acad Med. 2014;89(8):S73-S77. https://doi. org/10.1097/ACM.0000000000000328

11. Nehiley JM. How to conduct a Delphi study [homepage on the Internet]. 2001 [cited 2015 Aug 15]. Available from: http://www.dse.vic.gov.au/effectiveengagement/toolkit/tool-delphi-study

12. Jenkins $L$, Mash $B$, Derese $A$. The national portfolio of learning for postgraduate family medicine training in South Africa: Experiences of registrars and family medicine training in South Africa: Experiences of registrars and
supervisors in clinical practice. BMC Med Educ. 2013;13(1):1-13. https://doi. supervisors in clinical practice. BM
org/10.1186/1472-6920-13-149

13. Mash R, Ogunbanjo G, Naidoo C, Hellenberg D. The contribution of family physicians to district health services: A national position paper for South Africa. S Afr Fam Pract. 2015;57(3):54-61.

14. Wetmore SJ, Rivet C, Tepper J, Tatemichi S, Donoff M, Rainsberry P. Defining core procedure skills for Canadian family medicine training. Can Fam Physician. 2005;51(10):1364-1365.

15. Sylvester S, Magin P, Sweeney K, Morgan S, Henderson K. Procedura skills in general practice vocational training. Aust Fam Physician. 2011;40(1): $50-54$.

16. Mash R, Almeida M, Wong WC, Kumar R, Von Pressentin KB. The roles and training of primary care doctors: China, India, Brazil and South Africa. Hum Resour Health. 2015;13(1):1-13. https://doi.org/10.1186/s12960-015-0090-7 